\title{
TDP-43 Prions
}

\author{
Takashi Nonaka and Masato Hasegawa \\ Dementia Research Project, Tokyo Metropolitan Institute of Medical Science, Setagaya-ku, Tokyo, \\ Japan 156-8506 \\ Correspondence: nonaka-tk@igakuken.or.jp; hasegawa-ms@igakuken.or.jp
}

The most common neurodegenerative diseases, such as Alzheimer's, Parkinson's, and amyotrophic lateral sclerosis, are all protein-misfolding diseases and are characterized by the presence of disease-specific protein aggregates in affected neuronal cells. Recent studies have shown that, like tau and $\alpha$-synuclein, TAR-DNA binding protein of $43 \mathrm{kDa}$ (TDP-43) can form aggregates in vitro in a seed-dependent, self-templating, prion-like manner. Insoluble TDP-43 prepared from the brains of patients has been classified into several strains, which can be transferred from cell to cell in vitro, suggesting the involvement of mechanisms reminiscent of those by which prions spread through the nervous system. The idea that aberrant TDP-43 aggregates propagate in a prion-like manner between cells presents the possibility of novel therapeutic strategies to block spreading of these aggregates throughout the brain.

M ost neurodegenerative diseases, such as Alzheimer's disease (AD), Parkinson's disease (PD), and amyotrophic lateral sclerosis (ALS), have similar pathological features, and neuronal cells from the brains of these patients contain aberrant protein aggregates that pathologically characterize each disease. Neurofibrillary tangles (NFTs) that are predominantly made up of tau protein and Lewy bodies (LBs) consisting predominantly of $\alpha$-synuclein are major pathological protein inclusions found in $\mathrm{AD}$ and PD, respectively. Misfolded tau and $\alpha$ synuclein are thought to assemble into ordered aggregates in affected brain cells, but the molecular mechanisms by which these aggregates form in neuronal cells and induce cell death remain largely unknown. However, recent studies using cultured cells and mice have indicated that these protein aggregates are formed in a seed- dependent and self-templating manner and have prion-like properties. These results are consistent with earlier findings that tau and $\alpha$-synuclein pathology spreads in a stereotypical temporal and topological manner (Braak and Braak 1991; Braak et al. 2003). Furthermore, fetal mesencephalic grafts in the striatum of PD patients eventually develop Lewy bodies, indicating that pathological $\alpha$-synuclein could be transmitted from diseased striatal neurons to grafted neurons (Kordower et al. 2008; Li et al. 2008). Indeed, tau and $\alpha$-synuclein aggregates were shown to be transferred from cell to cell in vitro and in vivo (Clavaguera et al. 2009; Desplats et al. 2009; Frost et al. 2009; Luk et al. 2009, 2012a,b; Goedert et al. 2010; Nonaka et al. 2010, 2016; de Calignon et al. 2012; Liu et al. 2012; MasudaSuzukake et al. 2013, 2014). Therefore, prionlike propagation of aberrant protein aggregates

Editor: Stanley B. Prusiner

Additional Perspectives on Prion Diseases available at www.perspectivesinmedicine.org

Copyright (C) 2018 Cold Spring Harbor Laboratory Press; all rights reserved; doi: 10.1101/cshperspect.a024463

Cite this article as Cold Spring Harb Perspect Med 2018;8:a024463 
T. Nonaka and M. Hasegawa

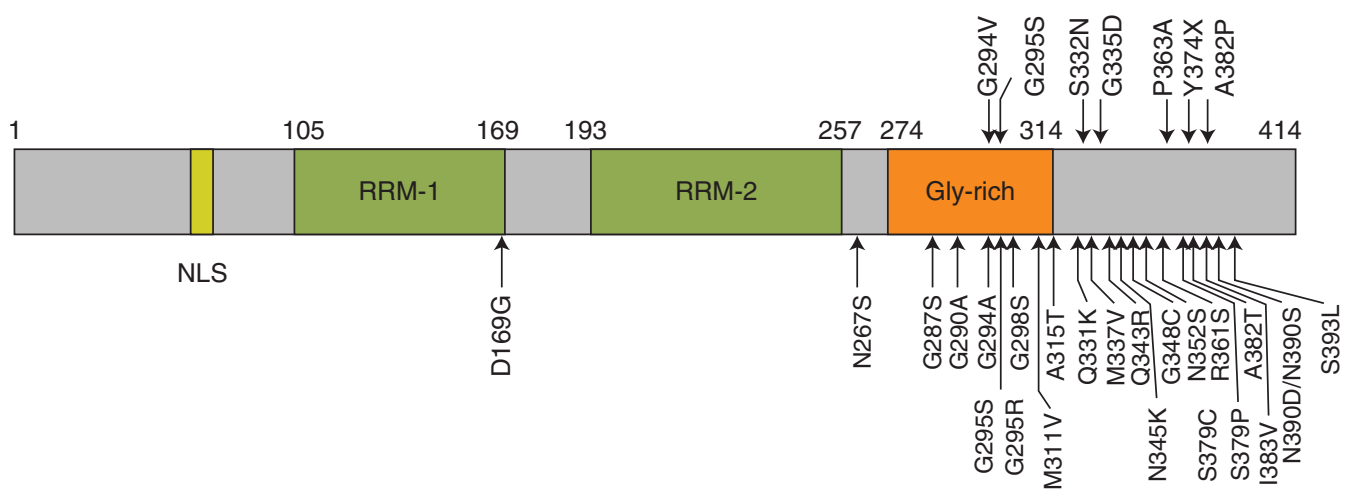

Figure 1. Schematic diagram of TDP-43 functional regions: NLS, nuclear localization signal; RRM, RNArecognition motif; Gly-rich, glycine-rich domain. Missense mutations in the TARDBP gene identified in patients with ALS and FTLD-TDP are indicated with arrows.

may play a key role in the pathogenesis of many neurodegenerative diseases. In this work, we review the evidence that TDP-43 also has prionlike properties, which are related to the pathogenesis of diseases in which TDP-43 aggregates are found.

TDP-43

TDP-43 is a 414-amino-acid protein containing a nuclear localization signal (NLS) and two RNA recognition motifs (RRMs) followed by a glycine-rich domain (Fig. 1). This protein belongs to the heterogeneous nuclear ribonucleoprotein (hnRNP) family and is a multifunctional DNA- and RNA-binding protein that is involved in many cellular processes, including RNA transcription, alternative splicing, and mRNA stability regulation (Wang et al. 2004; Buratti and Baralle 2008; Lagier-Tourenne et al. 2010; Ling et al. 2013; for an additional review of TDP-43, see Guo and Shorter 2016). The $\mathrm{NH}_{2}$-terminal portion of TDP-43, including these functional RRMs, is thought to have a folded conformation (Lukavsky et al. 2013), whereas the $\mathrm{COOH}$-terminal portion is unstructured. The $\mathrm{COOH}$-terminal region contains many glycine residues, forming a glycine-rich domain that interacts with other hnRNPs to regulate splicing. In 2006, TDP-43 was identified as the major component protein of ubiquitin-positive and tau-negative intracel- lular inclusions present in the brains and/or spinal cords of patients with frontotemporal lobar degeneration (FTLD) and ALS (Arai et al. 2006; Neumann et al. 2006). Subsequent immunohistochemical studies also showed abnormal accumulation of TDP-43 in neurodegenerative disorders other than FTLD and ALS, including ALS/parkinsonism dementia complex of Guam (Hasegawa et al. 2007; Geser et al. 2008), Alzheimer's disease (AD) (AmadorOrtiz et al. 2007; Higashi et al. 2007; Arai et al. 2009), dementia with Lewy bodies (DLBs) (Higashi et al. 2007; Nakashima-Yasuda et al. 2007; Arai et al. 2009), Pick's disease (Arai et al. 2006; Freeman et al. 2008; Lin and Dickson 2008), argyrophilic grain disease (Fujishiro et al. 2009), and corticobasal degeneration (Uryu et al. 2008). Collectively, these neurodegenerative diseases with TDP-43-immunoreactive pathology are named TDP-43 proteinopathies. In 2008, mutations in the TDP-43 gene TARDBP were discovered in familial and sporadic cases of ALS and FTLD (Pesiridis et al. 2009), indicating that abnormality of the TDP- 43 protein is associated with neurodegeneration. Pathogenic mutations in the TARDBP gene are mostly located in the $\mathrm{COOH}$-terminal glycine-rich region.

\section{ABNORMAL TDP-43 IN DISEASED BRAINS}

Biochemical and immunohistochemical studies have shown that pathological TDP-43 de- 
posited in the brains of patients has characteristic features of intracellular amyloid-like proteins, similar to those seen in tauopathies and $\alpha$-synucleinopathies. Namely, it is hyperphosphorylated, ubiquitinated (also p62-positive), and abnormally cleaved to generate $\mathrm{COOH}$ terminal fragments (CTFs) (Arai et al. 2006; Neumann et al. 2006; Hasegawa et al. 2008). Ser403/404 and Ser409/410 are the major phosphorylation sites of insoluble TDP-43 in diseased brains. The $\mathrm{COOH}$-terminal region of TDP-43 seems to have sequence similarities to prion proteins (Guo et al. 2011), suggesting that the $\mathrm{COOH}$-terminal prion-like domain plays an important role in TDP-43 proteinopathy. Indeed, TDP-43 CTFs produced in the brains of patients with FTLD-TDP were reported to be aggregation prone in cultured cells (Igaz et al. 2009; Nonaka et al. 2009). Furthermore, it was shown that TDP-43 is deposited as abnormal filaments of $\sim 15 \mathrm{~nm}$ in diameter (Hasegawa et al. 2008; Nonaka et al. 2013), and TDP-43immunoreactive inclusions in FTLD-TDP and ALS are thioflavin-S positive (Bigio et al. 2013), indicating that TDP-43 is accumulated as amyloid-like fibrils in the brains of patients with these diseases.

\section{CELLULAR TOXICITY OF TDP-43}

Neurotoxicity of TDP-43 remains disputed, as is also the case in tauopathies and $\alpha$-synucleinopathies. It continues to be a matter of debate whether abnormal TDP-43 aggregates or the fibrils themselves have a toxic effect; which is the most toxic species among the monomer, oligomer, and fibrils; and whether neurons undergo cell death by gain-of-toxic-function, loss-offunction, or another mechanism. Because many missense mutations in the TARDBP gene were identified in patients with ALS or FTLD-TDP, toxic gain-of-function of TDP-43 may be related to neuronal degeneration. However, in most sporadic cases of TDP-43 proteinopathy, no TARDBP mutations are identified, suggesting that expressional or conformational change of wild-type TDP-43 itself can cause the disease. Overexpression of wild-type TDP-43 causes motor neuron degeneration in yeast, mice, and rats (Johnson et al. 2008; Tatom et al. 2009; Wils et al. 2010). However, these phenotypes are probably attributable to increased levels of TDP-43, and the phosphorylated TDP-43 inclusions found in TDP-43 proteinopathy brains are not produced in these models, which, therefore, may not be genuine disease models of human TDP-43 proteinopathy.

We showed that overexpression of fulllength TDP-43 in SH-SY5Y cells caused significant cell death, suppression of cell growth, and induction of apoptosis, without formation of intracellular inclusions of TDP-43 (Yamashita et al. 2014). Several studies showing that endogenous TDP-43 expression is tightly regulated and is critical for survival are also consistent with our findings. Knockout of TARDBP in mice led to embryonic lethality (Chiang et al. 2010; Kraemer et al. 2010; Sephton et al. 2010; Wu et al. 2010), heterozygous knockout mice developed motor impairments with age (Kraemer et al.2010), and conditional knockout mice showed rapid postnatal lethality (Chiang et al. 2010). TDP-43 is also regulated at the mRNA level through a negative feedback loop (Ayala et al. 2011). These studies indicate that cellular TDP-43 levels are under tight control, and perturbation of normal TDP-43 function is detrimental.

The formation of cellular aggregates composed of TDP-43 CTF is also cytotoxic, causing a significant decrease of BrdU uptake; sequestration of RNA polymerase II, the specificity protein 1 (Sp1), and CAMP-response-element-binding protein (CREB) into cytoplasmic aggregates of TDP-43 CTF; and decreased transcriptional activities of Sp1 and CREB. Furthermore, RNA polymerase II co-localized with these inclusions in both cultured cells and FTLD-TDP brain (Yamashita et al. 2014). These findings are consistent with the idea that transcriptional deregulation plays a critical role in the degenerative cascade in TDP-43 proteinopathy.

\section{TDP-43 STRAINS IN PROTEINOPATHY}

TDP-43 proteinopathy can be classified into several subtypes, which are closely correlat- 
ed with clinicopathological phenotypes. In FTLD-TDP, TDP-43 pathology is distinguished into four histological subtypes (types A-D) based on the predominant type of TDP-43-positive structures: Type A is primarily seen in FTLD-TDP with the PGRN mutation; type B is seen in ALS and FTLD-MND; type C is representative of sporadic FTLD-TDP, showing impairment of semantic memory; and type D refers to the pathology associated with inclusion body myopathy with early onset Paget's disease and frontotemporal dementia caused by valosin-containing protein (VCP) mutations (Mackenzie et al. 2011). Immunoblotting of the Sarkosyl-insoluble fraction prepared from controls and FTLD-TDP and ALS cases with our antiphosphorylated TDP-43 antibody (directed at Ser409/Ser410) revealed that hyperphosphorylated full-length TDP-43 at $\sim 45 \mathrm{kDa}$, smearing substances, and CTFs at $18-26 \mathrm{kDa}$ are the major abnormal species of TDP-43 present in FTLD-TDP and ALS, but not in control brains (Hasegawa et al. 2008; Inukai et al. 2008).

The immunoblot analyses also revealed that the band patterns of the CTF of insoluble TDP-43 differed between neuropathological subtypes, indicating that the TDP-43 proteinopathies subclassified by neuropathological differences can also be distinguished biochemically (Hasegawa et al. 2008, 2011). Differences of the banding pattern of CTF suggest that the cleavage sites of insoluble TDP-43 are slightly different among these diseases. Therefore, the different band patterns of insoluble TDP-43 CTF deposited in TDP-43 proteinopathy brains represent different conformations of insoluble TDP-43 in brains of patients. Similar differences in the biochemical banding patterns were reported in prion diseases, Creutzfeldt-Jakob disease (CJD), and bovine spongiform encephalopathy (BSE) (Collinge et al. 1996). Proteinase-resistant prions from variant CJD cases showed a characteristically different banding pattern from that in sporadic CJD cases, and the pattern was indistinguishable from that of mice infected with BSE prions. This is biochemical evidence that BSE prions were transmitted from bovines to humans.
Tsuji et al. investigated whether the banding patterns of protease-resistant TDP-43 might reflect different TDP-43 strain types and characterized the TDP-43 CTF banding patterns in multiple regions of the CNS. They observed at least three $\mathrm{C}$-terminal banding patterns in TDP-43 proteinopathy brains and found that the banding patterns in different brain regions and spinal cord were indistinguishable in individual patients (Tsuji et al. 2012). This result clearly shows that the same form of insoluble TDP-43 is deposited in different brain regions. In other words, it seems likely that abnormal protein aggregates produced in cells are transferred to different regions and serve as seeds for further aggregation; alternatively, occurrence of the same conformational change synchronously in different brain regions seems implausible. In addition, similar to the progression and spreading patterns of tau and $\alpha$-synuclein pathology throughout the brains of patients, sequential propagation of phosphorylated TDP-43 pathology with 1-4 neuropathological disease stages has been proposed (Brettschneider et al. 2013). Thus, there is pathological and biochemical evidence that abnormal TDP-43 is transmitted from cell to cell and propagates like prions in vivo.

\section{CELLULAR MODELS FOR SEEDED AGGREGATION OF TDP-43}

Like tau and $\alpha$-synuclein, TDP-43 is also thought to aggregate in a seed-dependent and self-templating manner in vitro and in vivo. Indeed, two in vitro studies showing seeded aggregation of TDP-43 in cultured cells were reported. Furukawa et al. (2011) found that transduction of in vitro insoluble TDP-43 fibrils into cultured cells triggered aggregation of intracellular TDP-43. The intracellular aggregates of TDP-43 produced in the cultured cells were Sarkosyl-insoluble and ubiquitinated, but not phosphorylated, thus recapitulating only in part the characteristic properties of TDP-43 inclusions found in brains of patients with TDP43 proteinopathy. We reported prion-like properties of pathological TDP-43 aggregates from diseased brains using a unique cellular model 
for TDP-43 aggregation (Nonaka et al. 2013). We used a Sarkosyl-insoluble fraction containing insoluble TDP-43 prepared from ALS and FTLD-TDP brains as seeds, instead of recombinant TDP-43 fibrils. When insoluble TDP-43 was introduced into cells transiently transfected with a plasmid encoding TDP-43, phosphorylated, ubiquitinated, and fragmented TDP-43 was aggregated in a self-templating manner, perfectly recapitulating all the characteristic properties of TDP-43 inclusions found in the brains of patients with ALS and FTLD-TDP. Interestingly, time-course experiments using this cellular model showed that aggregation of full-length TDP-43 precedes generation of TDP-43 CTFs, suggesting that the production of CTFs is not essential for the formation of intracellular TDP-43 aggregates. We also observed that intracellular aggregate formation of TDP-43 induced death of cultured cells, probably by causing proteasome dysfunction.

\section{PRION-LIKE PROPERTIES OF TDP-43 AGGREGATES}

As described above, TDP-43 proteinopathy is classified into four types based on the predominant TDP-43-positive structures. Each type is also characterized biochemically by distinct patterns of insoluble TDP-43 CTFs detected with our anti-phosphoTDP-43 antibody. We prepared Sarkosyl-insoluble fractions from three types of brains (types A, B, and C) and introduced them as seeds into cells expressing a plasmid encoding TDP-43. The banding patterns of CTFs in the insoluble fraction of cells expressing TDP-43 in the presence of each type of seed were different from each other, but quite similar to that of insoluble TDP-43 prepared as seeds from the corresponding patients (type A, B, or C), indicating that plasmid-derived TDP-43 is aggregated in a template-dependent manner in the presence of each type of seed (Fig. 2). These results suggest that seed-dependent TDP-43 aggregation, like prion aggregation, occurs in a self-templating manner, and that there are several strains of insoluble TDP-43 associated with diseased brains, as is generally the case for pathogenic prions.
We further investigated whether insoluble TDP-43 from the brains of patients has prionlike characteristics (Nonaka et al. 2013). The results indicated that insoluble fraction from cells harboring TDP-43 aggregates can also trigger intracellular TDP-43 aggregation, and the seeding ability of insoluble TDP-43 was unaffected by heat or proteinase treatment, but was abrogated by formic acid. Indeed, the type A strain of insoluble TDP-43 was most stable to heat treatment, but type $\mathrm{B}$ and type $\mathrm{C}$ strains were not, clearly indicating that these strains have different prion-like characteristics. Interestingly, by means of co-culture experiments using cells including TDP-43 aggregates and cells without any aggregates, we also found that phosphorylated TDP-43 aggregates were propagated between cultured cells, as shown in Figure 3. Taken together, these results clearly show that insoluble TDP-43 strains from diseased brains have prion-like properties.

\section{POSSIBLE MECHANISMS UNDERLYING CELL-TO-CELL TRANSFER OF AGGREGATED PROTEINS}

It is thought that prion-like aggregates are released from cells and taken up by neighboring cells or cells connected to those containing aggregates by synaptic contact, and then they serve as nuclei for further aggregation. However, the mechanisms underlying propagation of protein aggregates between cells are not well understood. In the case of prions, it was reported that prions are transferred from cell to cell through exosomes and tunneling nanotubes (Fevrier et al. 2004; Gousset et al. 2009).

Exosomes are small vesicles of endocytic origin that are released by most living cells; they contain proteins, lipids, and RNA. After exosomes have been released into the extracellular space, they can be endocytosed by neighboring cells. If the aggregates are transferred through exosomes, they could be fused with the cell membrane or endosomal membrane, and then the aggregates would diffuse across the endosomal membrane into the cytoplasm (Goedert et al. 2010).

We also examined whether TDP-43 aggregates are transmitted from cell to cell via exo- 
T. Nonaka and M. Hasegawa

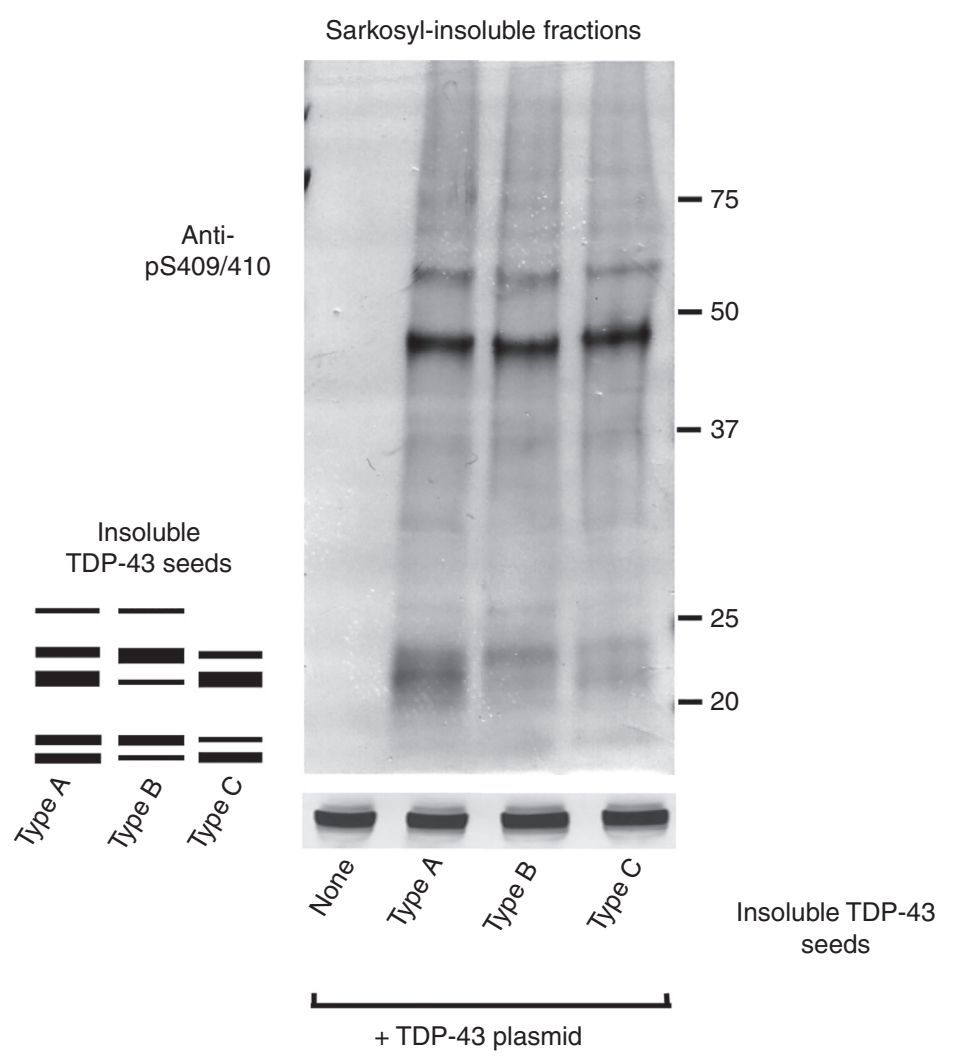

Figure 2. Insoluble TDP-43 from the brains of patients serves as a template for the formation of intracellular TDP-43 aggregates in cells expressing a plasmid encoding TDP-43. Comparison of band patterns of Sarkosylinsoluble fractions from cells treated with insoluble TDP-43 seeds prepared from the brains of patients with type A, B, or C TDP-43 proteinopathy (Mackenzie et al. 2011). A schematic diagram of the banding pattern of TDP-43 $\mathrm{COOH}$-terminal fragments (CTFs) observed from the three different TDP-43 types is also presented. Blots were probed using anti-phosphorylated TDP-43 (pS409/410). Molecular weight markers of migrated protein standards are shown in $\mathrm{kDa}$.

somes. Immunoblot analyses showed that in cells containing TDP-43 aggregates, full-length TDP-43 in the exosome fraction was significantly increased compared with that in control cells without TDP-43 aggregates, supporting the idea that exosomes may contribute to the release of intracellular TDP-43 aggregates. Further investigation is needed to elucidate in detail the mechanisms of intercellular propagation of protein aggregates in vitro and in vivo.

To study the mechanisms of propagation of aggregated TDP-43 in vivo, we need animal models of TDP-43 proteinopathy that almost perfectly recapitulate the pathology of TDP-43 proteinopathy in the human brain. In the case of mouse models of seeded aggregation of tau or $\alpha$-synuclein, intracerebral injections of recombinant protein fibrils or homogenates including insoluble tau or $\alpha$-synuclein from patient brains induced abnormal pathology not only in tau- or $\alpha$-synuclein-expressing transgenic ( $\mathrm{Tg}$ ) mice, but also in non- $\mathrm{Tg}$ wild-type mice. In the case of TDP-43, it was not easy to purify recombinant soluble protein, because it tends to form insoluble inclusion bodies in Escherichia coli. Therefore, it may be better to use ALS or FTLD-TDP brain homogenates containing insoluble TDP-43 as seeds for stereotaxic injection into mouse brain. Recently, a simplified purification method for soluble 

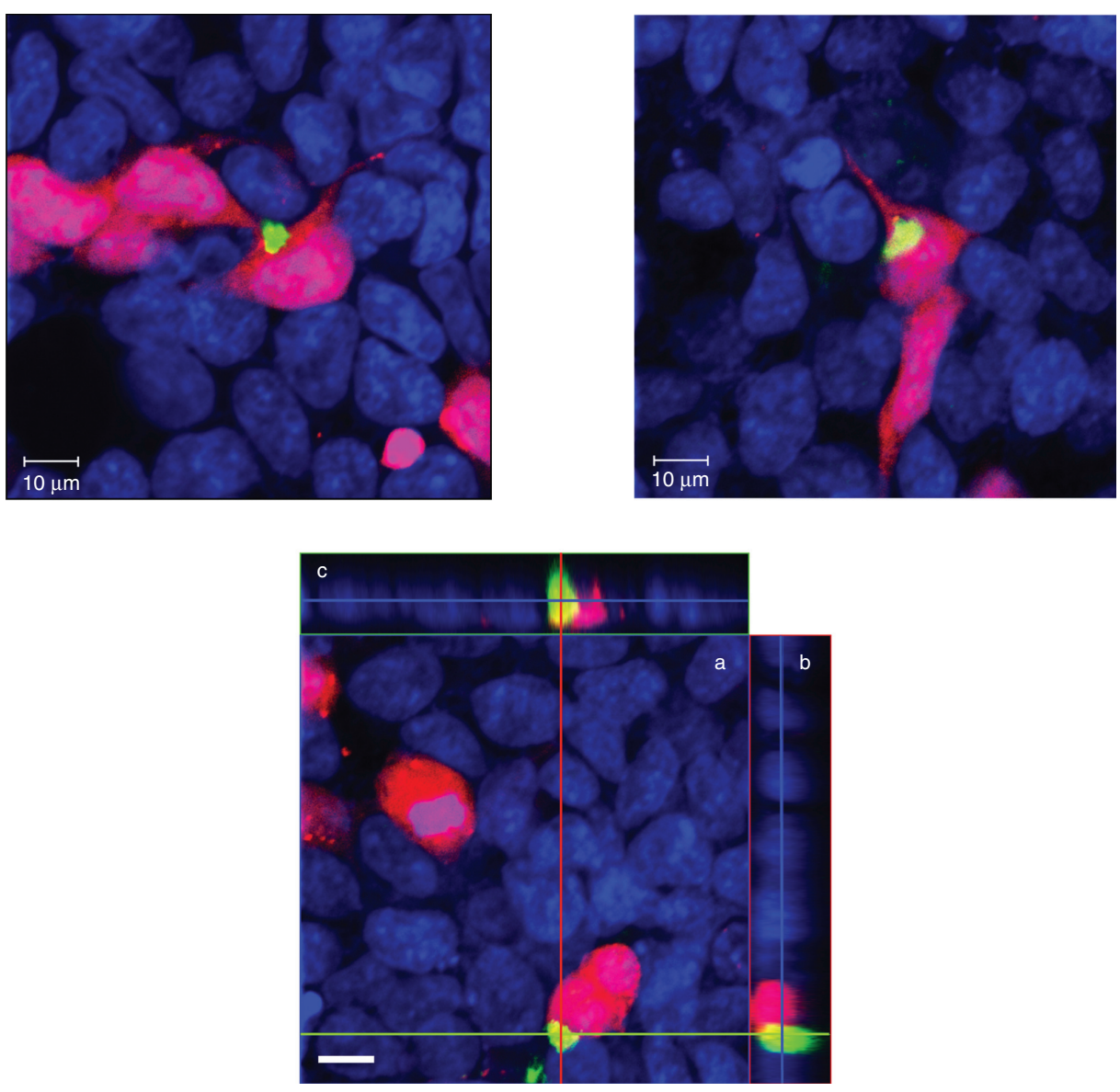

Figure 3. Intracellular TDP-43 aggregates are transmitted from cell to cell. (Upper) Co-culture of cells expressing DsRed and cells having intracellular TDP-43 aggregates in a 1:1 ratio. After incubation for 3 days, cells were stained with pS409/410 (green) and counter-stained with TO-PRO-3 (blue). Scale bars, $10 \mu \mathrm{m}$. (Lower) Cross sections of reconstructed TDP-43 aggregates in these co-cultured cells. (a) Optical section $(x-y)$ at the depth indicated with blue lines in $b$ and $c$. (b) Cross-sectional $y$ - $z$ image along the green line indicated in $a$. (c) Crosssectional $x-z$ image along the red line indicated in $a$. Scale bar, $10 \mu \mathrm{m}$.

untagged TDP-43 was reported (Carlomagno et al. 2014). This method should make it possible to prepare in vitro TDP-43 aggregates for injection into brains of TDP-43-expressing Tg or wild-type mice. Mouse models of seeded aggregation of TDP-43 may contribute to the discovery of new therapeutic agents for TDP-43 proteinopathy.

\section{CONCLUDING REMARKS}

Initially, it was believed that neurodegenerative diseases such as $\mathrm{AD}, \mathrm{PD}$, and ALS develop in a cell-autonomous manner, implying that aberrant protein aggregates form independently in affected neurons (Goedert et al. 2010). However, recent studies support the new concept that the onset and progression of these diseases, including TDP-43 proteinopathy, are associated with propagation of protein aggregates between neuronal cells, as shown in Figure 4. If this is the case, suppression of propagation of aggregated proteins may be a key therapeutic target for many common neurodegenerative diseases. 
T. Nonaka and M. Hasegawa

Seed-dependent and self-templating aggregation

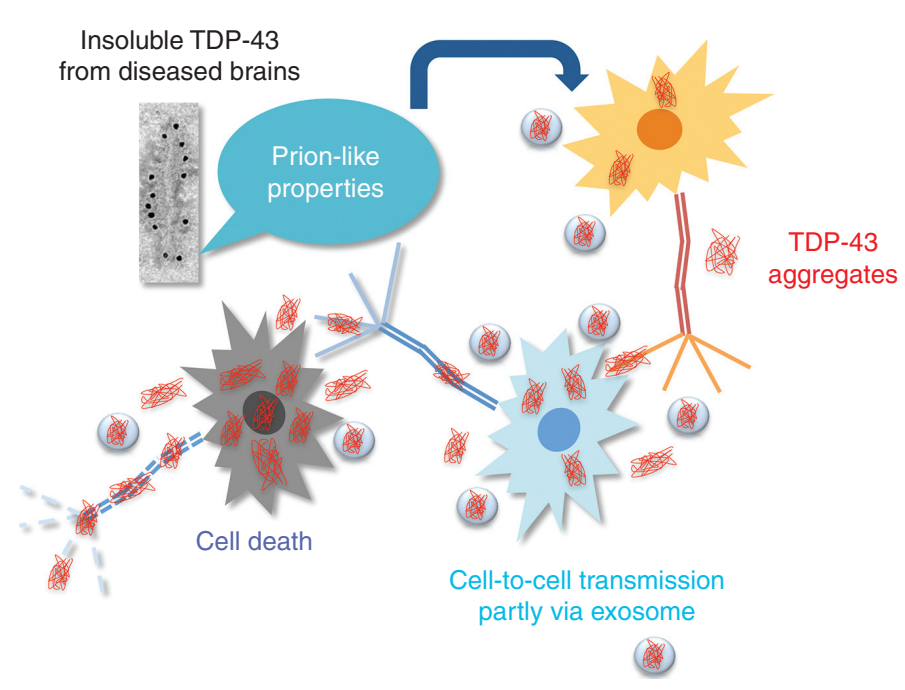

Figure 4. Seed-dependent and self-templating intracellular TDP-43 aggregation. The mechanisms by which intracellular aggregates cause cell death are proposed to be as follows: Insoluble TDP-43 deposited as amyloidlike fibrils is produced or taken up in the first cell and released into the extracellular space via membrane leakage or exosome. Introduced aggregates nucleate additional intracellular aggregation in adjacent cells. Increased levels of aggregates cause cellular dysfunction and, finally, cell death.

\section{ACKNOWLEDGMENTS}

This work is supported by a Grant-in-Aid for Scientific Research on Innovative Area "Brain Environment" (MEXT KAKENHI 26111730) and a grant from Takeda Science Foundation to T.N.

\section{REFERENCES}

${ }^{*}$ Reference is also in this collection.

Amador-Ortiz C, Lin WL, Ahmed Z, Personett D, Davies P, Duara R, Graff-Radford NR, Hutton ML, Dickson DW. 2007. TDP-43 immunoreactivity in hippocampal sclerosis and Alzheimer's disease. Ann Neurol 61: 435-445.

Arai T, Hasegawa M, Akiyama H, Ikeda K, Nonaka T, Mori H, Mann D, Tsuchiya K, Yoshida M, Hashizume Y, et al. 2006. TDP-43 is a component of ubiquitin-positive taunegative inclusions in frontotemporal lobar degeneration and amyotrophic lateral sclerosis. Biochem Biophys Res Commun 351: 602-611.

Arai T, Mackenzie IR, Hasegawa M, Nonoka T, Niizato K, Tsuchiya K, Iritani S, Onaya M, Akiyama H. 2009. Phosphorylated TDP-43 in Alzheimer's disease and dementia with Lewy bodies. Acta Neuropathol 117: 125-136.

Ayala YM, De Conti L, Avendaño-Vázquez SE, Dhir A, Romano M, D’Ambrogio A, Tollervey J, Ule J, Baralle M,
Buratti E, et al. 2011. TDP-43 regulates its mRNA levels through a negative feedback loop. EMBO J 30: 277-288.

Bigio EH, Wu JY, Deng HX, Bit-Ivan EN, Mao Q, Ganti R, Peterson M, Siddique N, Geula C, Siddique T, et al. 2013. Inclusions in frontotemporal lobar degeneration with TDP-43 proteinopathy (FTLD-TDP) and amyotrophic lateral sclerosis (ALS), but not FTLD with FUS proteinopathy (FTLD-FUS), have properties of amyloid. Acto Neuropathol 125: 463-465.

Braak H, Braak E. 1991. Neuropathological stageing of Alzheimer-related changes. Acta Neuropathol 82: 239-259.

Braak H, Del Tredici K, Rüb U, de Vos RA, Jansen Steur EN, Braak E. 2003. Staging of brain pathology related to sporadic Parkinson's disease. Neurobiol Aging 24: 197211.

Brettschneider J, Del Tredici K, Toledo JB, Robinson JL, Irwin DJ, Grossman M, Suh E, Van Deerlin VM, Wood EM, Baek Y, et al. 2013. Stages of pTDP-43 pathology in amyotrophic lateral sclerosis. Ann Neurol 74: 20-38.

Buratti E, Baralle FE. 2008. Multiple roles of TDP-43 in gene expression, splicing regulation, and human disease. Front Biosci 13: 867-878.

Carlomagno Y, Zhang Y, Davis M, Lin WL, Cook C, Dunmore J, Tay W, Menkosky K, Cao X, Petrucelli L, et al. 2014. Casein kinase II induced polymerization of soluble TDP-43 into filaments is inhibited by heat shock proteins. PLoS ONE 9: e90452.

Chiang PM, Ling J, Jeong YH, Price DL, Aja SM, Wong PC. 2010. Deletion of TDP-43 down-regulates Tbc1d1, a gene 
TDP-43 Prions

linked to obesity, and alters body fat metabolism. Proc Natl Acad Sci 107: 16320-16324.

Clavaguera F, Bolmont T, Crowther RA, Abramowski D, Frank S, Probst A, Fraser G, Stalder AK, Beibel M, Staufenbiel M, et al. 2009. Transmission and spreading of tauopathy in transgenic mouse brain. Nat Cell Biol 11: 909-913.

Collinge J, Sidle KC, Meads J, Ironside J, Hill AF. 1996 Molecular analysis of prion strain variation and the aetiology of 'new variant' CJD. Nature 383: 685-690.

de Calignon A, Polydoro M, Suárez-Calvet M, William C, Adamowicz DH, Kopeikina KJ, Pitstick R, Sahara N, Ashe KH, Carlson GA, et al. 2012. Propagation of tau pathology in a model of early Alzheimer's disease. Neuron 73: 685-697.

Desplats P, Lee HJ, Bae EJ, Patrick C, Rockenstein E, Crews L, Spencer B, Masliah E, Lee SJ. 2009. Inclusion formation and neuronal cell death through neuron-to-neuron transmission of $\alpha$-synuclein. Proc Natl Acad Sci 106: 13010-13015.

Fevrier B, Vilette D, Archer F, Loew D, Faigle W, Vidal M, Laude H, Raposo G. 2004. Cells release prions in association with exosomes. Proc Natl Acad Sci 101: 9683-9688.

Freeman SH, Spires-Jones T, Hyman BT, Growdon JH, Frosch MP. 2008. TAR-DNA binding protein 43 in Pick disease. J Neuropathol Exp Neurol 67: 62-67.

Frost B, Jacks RL, Diamond MI. 2009. Propagation of tau misfolding from the outside to the inside of a cell. $J$ Biol Chem 284: 12845-12852.

Fujishiro H, Uchikado H, Arai T, Hasegawa M, Akiyama H, Yokota O, Tsuchiya K, Togo T, Iseki E, Hirayasu Y. 2009. Accumulation of phosphorylated TDP-43 in brains of patients with argyrophilic grain disease. Acta Neuropathol 117: 151-158.

Furukawa Y, Kaneko K, Watanabe S, Yamanaka K, Nukina N. 2011. A seeding reaction recapitulates intracellular formation of Sarkosyl-insoluble transactivation response element (TAR) DNA-binding protein-43 inclusions. J Biol Chem 286: 18664-18672.

Geser F, Winton MJ, Kwong LK, Xu Y, Xie SX, Igaz LM, Garruto RM, Perl DP, Galasko D, Lee VM, et al. 2008. Pathological TDP-43 in parkinsonism-dementia complex and amyotrophic lateral sclerosis of Guam. Acta Neuropathol 115: 133-145.

Goedert M, Clavaguera F, Tolnay M. 2010. The propagation of prion-like protein inclusions in neurodegenerative diseases. Trends Neurosci 33: 317-325.

Gousset K, Schiff E, Langevin C, Marijanovic Z, Caputo A, Browman DT, Chenouard N, de Chaumont F, Martino A, Enninga J, et al. 2009. Prions hijack tunnelling nanotubes for intercellular spread. Nat Cell Biol 11: 328-336.

* Guo L, Shorter J. 2016. Biology and pathobiology of TDP-43 and emergent therapeutic strategies. Cold Spring Harb Perspect Med doi: 10.1101/cshperspect.a024554.

Guo W, Chen Y, Zhou X, Kar A, Ray P, Chen X, Rao EJ, Yang M, Ye H, Zhu L, et al. 2011. An ALS-associated mutation affecting TDP-43 enhances protein aggregation, fibril formation and neurotoxicity. Nat Struct Mol Biol 18: $822-830$.

Hasegawa M, Arai T, Akiyama H, Nonaka T, Mori H, Hashimoto T, Yamazaki M, Oyanagi K. 2007. TDP-43 is deposited in the Guam parkinsonism-dementia complex brains. Brain 130: 1386-1394.

Hasegawa M, Arai T, Nonaka T, Kametani F, Yoshida M, Hashizume Y, Beach TG, Buratti E, Baralle F, Morita M, et al. 2008. Phosphorylated TDP-43 in frontotemporal lobar degeneration and amyotrophic lateral sclerosis. Ann Neurol 64: 60-70.

Hasegawa M, Nonaka T, Tsuji H, Tamaoka A, Yamashita M, Kametani F, Yoshida M, Arai T, Akiyama H. 2011. Molecular dissection of TDP-43 proteinopathies. J Mol Neurosci 45: 480-485.

Higashi S, Iseki E, Yamamoto R, Minegishi M, Hino H, Fujisawa K, Togo T, Katsuse O, Uchikado H, Furukawa Y, et al. 2007. Concurrence of TDP-43, tau and $\alpha$-synuclein pathology in brains of Alzheimer's disease and dementia with Lewy bodies. Brain Res 1184: 284-294.

Igaz LM, Kwong LK, Chen-Plotkin A, Winton MJ, Unger TL, Xu Y, Neumann M, Trojanowski JQ, Lee VM. 2009. Expression of TDP-43 C-terminal fragments in vitro recapitulates pathological features of TDP-43 proteinopathies. J Biol Chem 284: 8516-8524.

Inukai Y, Nonaka T, Arai T, Yoshida M, Hashizume Y, Beach TG, Buratti E, Baralle FE, Akiyama H, Hisanaga S, et al. 2008. Abnormal phosphorylation of Ser409/410 of TDP43 in FTLD-U and ALS. FEBS Lett 582: 2899-2904.

Johnson BS, McCaffery JM, Lindquist S, Gitler AD. 2008. A yeast TDP-43 proteinopathy model: Exploring the molecular determinants of TDP-43 aggregation and cellular toxicity. Proc Natl Acad Sci 105: 6439-6444.

Kordower JH, Chu Y, Hauser RA, Freeman TB, Olanow CW 2008. Lewy body-like pathology in long-term embryonic nigral transplants in Parkinson's disease. Nat Med 14: 504-506.

Kraemer BC, Schuck T, Wheeler JM, Robinson LC, Trojanowski JQ, Lee VM, Schellenberg GD. 2010. Loss of murine TDP-43 disrupts motor function and plays an essential role in embryogenesis. Acta Neuropathol 119: 409419.

Lagier-Tourenne C, Polymenidou M, Cleveland DW. 2010. TDP-43 and FUS/TLS: Emerging roles in RNA processing and neurodegeneration. Hum Mol Genet 19: R46R64.

Li JY, Englund E, Holton JL, Soulet D, Hagell P, Lees AJ, Lashley T, Quinn NP, Rehncrona S, Björklund A, et al. 2008. Lewy bodies in grafted neurons in subjects with Parkinson's disease suggest host-to-graft disease propagation. Nat Med 14: 501-503.

Lin WL, Dickson DW. 2008. Ultrastructural localization of TDP-43 in filamentous neuronal inclusions in various neurodegenerative diseases. Acta Neuropathol 116: $205-$ 213.

Ling SC, Polymenidou M, Cleveland DW. 2013. Converging mechanisms in ALS and FTD: Disrupted RNA and protein homeostasis. Neuron 79: 416-438.

Liu L, Drouet V, Wu JW, Witter MP, Small SA, Clelland C, Duff K. 2012. Trans-synaptic spread of tau pathology in vivo. PLoS ONE 7: e31302.

Luk KC, Song C, O’Brien P, Stieber A, Branch JR, Brunden KR, Trojanowski JQ, Lee VM. 2009. Exogenous $\alpha$-synuclein fibrils seed the formation of Lewy body-like intracellular inclusions in cultured cells. Proc Natl Acad Sci 106: 20051-20056. 
T. Nonaka and M. Hasegawa

Luk KC, Kehm V, Carroll J, Zhang B, O’Brien P, Trojanowski JQ, Lee VM. 2012a. Pathological $\alpha$-synuclein transmission initiates Parkinson-like neurodegeneration in nontransgenic mice. Science 338: 949-953.

Luk KC, Kehm VM, Zhang B, O’Brien P, Trojanowski JQ, Lee VM. 2012b. Intracerebral inoculation of pathological $\alpha$ synuclein initiates a rapidly progressive neurodegenerative $\alpha$-synucleinopathy in mice. J Exp Med 209: 975-986.

Lukavsky PJ, Daujotyte D, Tollervey JR, Ule J, Stuani C, Buratti E, Baralle FE, Damberger FF, Allain FH. 2013. Molecular basis of UG-rich RNA recognition by the human splicing factor TDP-43. Nat Struct Mol Biol 20: 1443-1449.

Mackenzie IR, Neumann M, Baborie A, Sampathu DM, Du Plessis D, Jaros E, Perry RH, Trojanowski JQ, Mann DM, Lee VM. 2011. A harmonized classification system for FTLD-TDP pathology. Acta Neuropathol 122: 111-113.

Masuda-Suzukake M, Nonaka T, Hosokawa M, Oikawa T, Arai T, Akiyama H, Mann DM, Hasegawa M. 2013. Prion-like spreading of pathological $\alpha$-synuclein in brain. Brain 136: $1128-1138$.

Masuda-Suzukake M, Nonaka T, Hosokawa M, Kubo M, Shimozawa A, Akiyama H, Hasegawa M. 2014. Pathological $\alpha$-synuclein propagates through neural networks. Acta Neuropathol Commun 2: 88.

Nakashima-Yasuda H, Uryu K, Robinson J, Xie SX, Hurtig H, Duda JE, Arnold SE, Siderowf A, Grossman M, Leverenz JB, et al. 2007. Co-morbidity of TDP-43 proteinopathy in Lewy body related diseases. Acta Neuropathol 114: 221-229.

Neumann M, Sampathu DM, Kwong LK, Truax AC, Micsenyi MC, Chou TT, Bruce J, Schuck T, Grossman M, Clark CM, et al. 2006. Ubiquitinated TDP-43 in frontotemporal lobar degeneration and amyotrophic lateral sclerosis. Science 314: 130-133.

Nonaka T, Kametani F, Arai T, Akiyama H, Hasegawa M. 2009. Truncation and pathogenic mutations facilitate the formation of intracellular aggregates of TDP-43. Hum Mol Genet 18: 3353-3364.

Nonaka T, Watanabe ST, Iwatsubo T, Hasegawa M. 2010 Seeded aggregation and toxicity of $\alpha$-synuclein and tau: Cellular models of neurodegenerative diseases. J Biol Chem 285: 34885-34898.

Nonaka T, Masuda-Suzukake M, Arai T, Hasegawa Y, Akatsu H, Obi T, Yoshida M, Murayama S, Mann DM,
Akiyama H, et al. 2013. Prion-like properties of pathological TDP-43 aggregates from diseased brains. Cell Rep 4: $124-134$.

Nonaka T, Watanabe S, Masuda M, Hasegawa M. 2016. U.S. Patent PCT/JP2006/324786.

Pesiridis GS, Lee VM, Trojanowski JQ. 2009. Mutations in TDP-43 link glycine-rich domain functions to amyotrophic lateral sclerosis. Hum Mol Genet 18: R156-R162.

Sephton CF, Good SK, Atkin S, Dewey CM, Mayer P III, Herz J, Yu G. 2010. TDP-43 is a developmentally regulated protein essential for early embryonic development. J Biol Chem 285: 6826-6834.

Tatom JB, Wang DB, Dayton RD, Skalli O, Hutton ML, Dickson DW, Klein RL. 2009. Mimicking aspects of frontotemporal lobar degeneration and Lou Gehrig's disease in rats via TDP-43 overexpression. Mol Ther 17: 607-613.

Tsuji H, Arai T, Kametani F, Nonaka T, Yamashita M, Suzukake M, Hosokawa M, Yoshida M, Hatsuta H, Takao M, et al. 2012. Molecular analysis and biochemical classification of TDP-43 proteinopathy. Brain 135: 3380-3391.

Uryu K, Nakashima-Yasuda H, Forman MS, Kwong LK, Clark CM, Grossman M, Miller BL, Kretzschmar HA, Lee VM, Trojanowski JQ, et al. 2008. Concomitant TAR-DNA-binding protein 43 pathology is present in Alzheimer disease and corticobasal degeneration but not in other tauopathies. J Neuropathol Exp Neurol 67: $555-564$.

Wang HY, Wang IF, Bose J, Shen CK. 2004. Structural diversity and functional implications of the eukaryotic TDP gene family. Genomics 83: 130-139.

Wils H, Kleinberger G, Janssens J, Pereson S, Joris G, Cuijt I, Smits V, Ceuterick-de Groote C, Van Broeckhoven C, Kumar-Singh S. 2010. TDP-43 transgenic mice develop spastic paralysis and neuronal inclusions characteristic of ALS and frontotemporal lobar degeneration. Proc Natl Acad Sci 107: 3858-3863.

Wu LS, Cheng WC, Hou SC, Yan YT, Jiang ST, Shen CK. 2010. TDP-43, a neuro-pathosignature factor, is essential for early mouse embryogenesis. Genesis 48: 56-62.

Yamashita M, Nonaka T, Hirai S, Miwa A, Okado H, Arai T, Hosokawa M, Akiyama H, Hasegawa M. 2014. Distinct pathways leading to TDP-43-induced cellular dysfunctions. Hum Mol Genet 23: 4345-4356. 


\section{$\&_{\mathrm{CSH}}^{\infty} \&$ Cold Spring Harbor

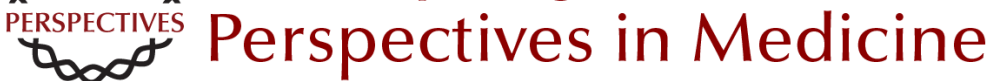

\section{TDP-43 Prions}

Takashi Nonaka and Masato Hasegawa

Cold Spring Harb Perspect Med 2018; doi: 10.1101/cshperspect.a024463 originally published online January 20, 2017

\section{Subject Collection Prion Diseases}

TDP-43 Prions

Takashi Nonaka and Masato Hasegawa

$\alpha$-Synuclein: Multiple System Atrophy Prions

Amanda L. Woerman, Joel C. Watts, Atsushi

Aoyagi, et al.

Genetics of Synucleinopathies

Robert L. Nussbaum

$\beta$-Amyloid Prions and the Pathobiology of

Alzheimer's Disease Joel C. Watts and Stanley B. Prusiner

Disease Mechanisms of C9ORF72 Repeat Expansions

Tania F. Gendron and Leonard Petrucelli

Chronic Traumatic Encephalopathy: Is Latency in

Symptom Onset Explained by Tau Propagation? Joshua Kriegel, Zachary Papadopoulos and Ann C. McKee

Noncerebral Amyloidoses: Aspects on Seeding,

Cross-Seeding, and Transmission

Gunilla T. Westermark, Marcus Fändrich,

Katarzyna Lundmark, et al.

Structural and Chemical Biology of Presenilin

Complexes

Douglas S. Johnson, Yue-Ming Li, Martin

Pettersson, et al.
Cell Biology and Pathophysiology of $\alpha$-Synuclein Jacqueline Burré, Manu Sharma and Thomas C. Südhof

Molecular Mechanisms of Chronic Wasting

Disease Prion Propagation Julie A. Moreno and Glenn C. Telling

Genetics of Amyotrophic Lateral Sclerosis Mehdi Ghasemi and Robert H. Brown, Jr.

The Genetics of C9orf72 Expansions Ilse Gijselinck, Marc Cruts and Christine Van Broeckhoven

Prion-Like Characteristics of

Polyglutamine-Containing Proteins Margaret M.P. Pearce and Ron R. Kopito

Therapeutic Strategies for Restoring Tau Homeostasis

Zapporah T. Young, Sue Ann Mok and Jason E. Gestwicki

Fused in Sarcoma Neuropathology in Neurodegenerative Disease Ian R.A. Mackenzie and Manuela Neumann

Experimental Models of Inherited PrP Prion

Diseases

Joel C. Watts and Stanley B. Prusiner

For additional articles in this collection, see http://perspectivesinmedicine.cshlp.org/cgi/collection/ 